\title{
Leiomyoma of the female urethra: A case report and review of the literature
}

\section{Kadında uretral leyomiyom: Olgu sunumu ve literatür eşliğinde değerlendirme}

Furkan ŞENDOĞAN $\odot$, Bülent EROL $\odot$, Muhammet ÇiçEK $\odot$, Tülay ZENGINKINET $\odot$, Turhan ÇAŞKURLU $\odot$

ABSTRACT

Urethral leiomyoma is a rare mesenchymal benign tumor of smooth muscle origin that is frequently seen in females. Only one hundred women and seven male cases have been reported in the literature. Urinary tract infection, palpable mass, dysuria, hematuria and acute urinary retention are the most commonly reported symptoms. Surgical removal is the first choice of treatment for these tumors In this report we presented a case of 34 year- old, postpartum woman with an urethral leiomyoma that caused lower urinary system symptoms.

Keywords: Urethral leiomyoma, hematuria, urethral mass
Öz

Üretral leyomiyom düz kastan köken alan nadir mezenşimal benign tümördür ve sıklıkla kadınlarda saptanır. Literatürde yalnızca 100 kadın ve 7 erkek vaka bildirilmiştir. Idrar yolu enfeksiyonu, palpabl kitle, dizüri, hematüri ve akut üriner retansiyon en çok bildirilen semptomlardır. Tedavide birinci seçenek kitlenin cerrahi çıkarılmasıdır. Bu makalede, 34 yaşında, postpartum dönemde uretral leiomyomu olan ve alt üriner sistem semptomlarına neden olan olgu sunulmuştur.

Anahtar kelimeler: Üretral leyomiyom, hematüri, üretral kitle

\section{GiRiş}

Üretral leiomyom nadir görülen, üretra düz kasından kaynaklanan benign mezenşimal tümördür ${ }^{1}$. Kadınlarda daha sık görülmektedir. Literatürde yaklaşık 100 kadın vaka mevcutken, erkeklerde yalnızca 7 vaka tanımlanmıştır². Uretral leiomyomun etiyolojisi hakkında net bir fikir birliği olmamakla birlikte, sıklıkla kadınlarda reproduktif dönemde saptanması hormonal bir altyapısının olabileceği hipotezini desteklemektedir ${ }^{3}$. Bu olgu sunumunda gebelik sonrası saptanan ve alt üriner sistem semptomlarına neden olan üretral leiomyom olgusu sunuldu.
OLGU

Otuz dört yaşında kadın hasta hematüri, dizüri ve ani idrara sıkışma semptomları ile kliniğe başvurdu. Hastanın öyküsünde iki gebeliği mevcut olup, her iki doğumun da vajinal doğum olarak sonuçlandığı ve distosi olmadığı hasta tarafından belirtildi. Gebeliği süresince jinekoloji polikliniğinde yapılan muayenelerde herhangi patoloji olmadığı bilgisi hastanın mevcut poliklinik başvurularından elde edildi. Son doğumundan 2 ay sonra semptomların geliştiği ve üretral lezyonun görünür hale geldiğini belirtti. Hastanın jinekolojik muayenesinde mid-üretradan doğan, meatusa uzanan ve meatusu tama yakın obstrukte eden, düzgün sınırlı yaklaşık $3 \times 2 \mathrm{~cm}$ boyutlarında kitle lez-

Received: 14.12 .2017

Accepted: 25.02 .2018

Istanbul Medeniyet University, Goztepe Training and Research Hospital, Department of ${ }^{1}$ Urology, ${ }^{2}$ Pathology, Istanbul, Turkey

Yazışma adresi: Furkan Şendoğan, Istanbul Medeniyet University, Goztepe Training and Research Hospital, Department of Urology, Istanbul, Turkey

e-mail: furkandg@hotmail.com

Yazarların ORCiD bilgileri:

F.Ş. 0000-0001-6865-018X, B.E. 0000-0003-2402-3373, M.Ç. 0000-0001-5478-3352, T.Z. 0000-0003-3056-2074, T.Ç. 0000-0002-4471-2670 
yon saptandı. Hastaya genel anestezi altında kitle eksizyonu ve tanısal sistoskopi operasyonu planlandı. Operasyon sırasında kitlenin mid-üretradan orijin aldığı saptandı ve kitle üretradan künt ve keskin diseksiyon ile eksize edildi (Figür 1). Cerrahi sınır ayrıca örneklendi. Sistoskopik incelemesinde sfinkterin intakt olduğu ve mesane içerisinde de ek patoloji olmadığı saptandı. Postoperatif 1 . gün sondası alınan, spontan miksiyonu saptanan ve ek yakınması olmayan hasta poliklinik kontrolü önerilerek taburcu edildi. Kitlenin patolojik incelemesinde atipi ve mitoz izlenmeyen ve immünohistokimyasal olarak aktin ve kaldesmosom pozitifliği saptanan düz kas hücrelerinin üretral leiomyom ile uyumlu olduğu belirtildi (Figür 2). Yapılan incelemede, cerrahi sınırın negatif olduğu raporlandı.

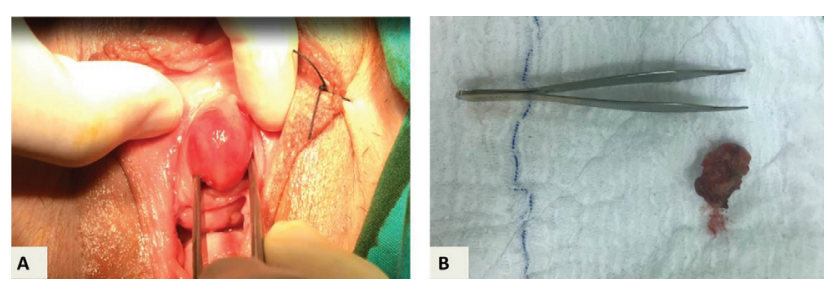

Figür 1. Peroperatif üretradan doğan ve meatusu tama yakın dolduran üretral kitle (A), postoperatif kitlenin komplet eksizyonu (B).

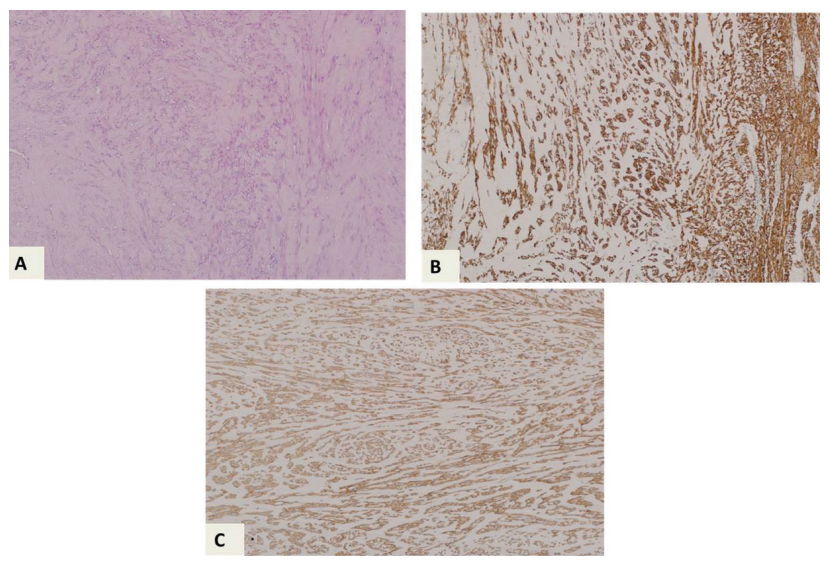

Figür 2. H\&E x100 büyütmede; atipi ve mitoz içermeyen düz kas hücreleri (A), immünohistokimyasal olarak aktin (B) ve kaldesmon (C) pozitifliği.

\section{TARTIŞMA}

Leiomyom, genitoüriner sistemde sıklıkla renal kapsülde görülen, düz kastan köken alan benign tümördür $r^{4}$. Buna rağmen, üretrada nadiren saptanır ${ }^{5}$.
Üretral leiomyom ilk olarak 1894 yılında Buttner tarafından tanımlanmıştır ${ }^{6}$. Bu tümörler herhangi bir yaşta oluşabileceği gibi sıklıkla 3. ve 4. dekadda ortaya çıkmakta ve vakaların yaklaşık \%80'inde proksimal üretradan kaynaklanmaktadır ${ }^{4}$. Leiomyomlar üç kategori altında sınıflandırılmaktadır. Bunlar kutanöz leiomyomlar, anjioleiomyomlar ve derin yumuşak doku leiomyomlarıdır. Üretral leiomyomlar, derin yumuşak doku leiomyomları adı altında sınıflandırılmaktadır. Bu tümörlerin sıklıkla gebelik döneminde büyüyüp postpartum dönemde regrese olması hormonal bir altyapısının olduğunu düşündürmektedir ${ }^{8}$. Olgumuzdaki üretral leiomyomun özellikle postpartum dönemde ortaya çıkması ve semptomatik olması, üretral leiomyomun patogenezinde farklı mekanizmaların da olabileceğini düşündürmektedir.

Hastalar palpabl kitle, hematüri, dizüri, akut üriner retansiyon ve üriner sistem enfeksiyonu gibi yakınmalarla kliniğe başvursa da hastaların \%23'ünden fazlası asemptomatiktir ${ }^{9}$. Ayrıntılı öykü ve fizik muayene üretral kitlelerin değerlendirilmesinde son derece önemlidir. Seçilmiş vakalarda ultrason (US), pelvik manyetik rezonans görüntüleme $(M R)$ ve bilgisayarlı tomografi (BT) gibi görüntüleme yöntemleri kullanılabilir. Üretral leiomyomlar US'de iyi sınırlı izo-hipoekoik homojen kitle olarak görüntülenirken, MR'da T1 ağırlıklı görüntülemede izointens kapsüle kitle, T2 ağırlıklı görüntülemede ise yoğun kontrast tutan kitle olarak görüntülenirler ${ }^{10}$. Görüntüleme yöntemleri tümörün tam lokalizasyonu, doku infiltrasyon derinliği, tümörün malignensi düşündüren özelliklerinin varlığı ve cerrahi eksizyonun planlanması hakkında bilgi verse de kesin tanı için kitlenin histopatolojik incelemesinin yapılması gerekmektedir ${ }^{4,11}$. Olgumuzda fizik muayenede kitlenin küçük, palpabl ve solid nitelikte olması, sınırlarının belirgin olması ve çevre dokulara invazyonuna dair fizik muayene bulgusunun olmamasından dolayı ek görüntüleme yöntemine gereksinim duyulmamıştır. Bu durum kitlenin histopatolojik incelemesinde cerrahi sınırın negatif olması ile doğrulanmaktadır.

Günümüzde üretral leiomyomun nadir saptanan bir durum olmasından dolayı hastalığın yönetimi ve te- 
davi algoritması geliştirilmemiştir. Önerilen tedavi yöntemi kitlenin komplet eksizyonudur ${ }^{9}$.

\section{SONUÇ}

Leiomyomlar benign düz kas tümörleridir ve nadiren üretrada saptanır. Kadınlarda ve özellikle reproduktif dönemde saptanması ve postpartum dönemde regresyon göstermesi hormonal bir altyapısının olduğunu düşündürse de olgumuzda postpartum ortaya çıkması patofizyolojisinde farklı mekanizmaların da olabileceğini düşündürmektedir.

\section{KAYNAKLAR}

1. Shield DE and Weiss RM. Leiomyoma of the female urethra. J Urol. 1973 Mar;109(3):430-1. https://doi.org/10.1016/S0022-5347(17)60443-9

2. Garrido Abad $P$, Fernández Arjona M, Herranz Fernández LM, et al. Leiomyoma of the male urethra: case report and review of the literature. Arch Esp Urol. 2010 Jan-Feb;63(1):71-4.

3. Migliari R, Buffardi A, and Mosso L. Female paraurethral leiomyoma: treatment and long-term follow-up. Int Urogynecol
J. 2015 Dec;26(12):1821-5. https://doi.org/10.1007/s00192-015-2776-8

4. Aslam R, Mohsin R, Mubarak M, et al. Leiomyoma of the female urethra with intermittent urinary retention: a case report. Middle East J Cancer. 2013;4(4):189-92.

5. Kumar SS, Gowri SR, Viswanathan P, et al. Urethral leiomyoma - a very rare entity. J Med Dent Sci. 2013; Vol. 2, Issue 47, November 25; Page: 9077-80.

6. Buttner: A case of myoma of the female urethra. Z Geburshe Gynak. 1894;28:135.

7. Rivière $P$, Bodin $R$, Bernard $G$, et al. Leiomyoma of the female urethra. Prog Urol. 2004 Dec;14(6):1196-8.

8. Ozel B, Ballard C. Urethral and paraurethral leiomyomas in the female patient. Int Urogynecol J Pelvic Floor Dysfunct. 2006 Jan;17(1):93-5. https://doi.org/10.1007/s00192-005-1316-3

9. Beng Kwang N, Naidu A, Yahaya A, Pei Shan L. Urethral Leiomyoma: A Rare Clinical Entity. Case Rep Surg. 2016;2016:6037104, Epub 2016 Nov 23.

10. Verma R, Mehra S, Garga UC, et al. Imaging diagnosis of urethral leiomyoma, usual tumour at an unusual location. J Clin Diagn Res. 2014 Nov;8(11):RD04-6. https://doi.org/10.7860/JCDR/2014/8697.5164

11. Hubert KC, Remer EM, Rackley RR, Goldman HB. Clinical and magnetic resonance imaging characteristics of vaginal and paraurethral leiomyomas: can they be diagnosed before surgery? BJU Int. 2010 Jun;105(12):1686-8.

https://doi.org/10.1111/j.1464-410X.2009.09046.x 